\title{
EXTRAÇÃO LÍQUIDO-LÍQUIDO APLICADA AO PROCESSO DE REFINO DE ETANOL COMBUSTÍVEL
}

\author{
G. M. K. PITOMBEIRA ${ }^{1}$, M. VIANNA ${ }^{1}$, V. TEODORO ${ }^{1}$, L. A. PERAZOLLI ${ }^{1}$, E. S. \\ MONTEIRO FILHO ${ }^{1}$ \\ ${ }^{1}$ Universidade Estadual Paulista, Instituto de Química de Araraquara, Departamento de \\ Bioquímica e Tecnologia \\ E-mail para contato: elias@iq.unesp.br
}

\begin{abstract}
RESUMO - O etanol já firmou-se como componente essencial na matriz energética brasileira. Um dos principais aspectos que podem ser abordados em sua produção é o consumo energético da planta, visto que as usinas atualmente são cada vez mais empresas produtoras de energia, com viés diversificador. Este trabalho visa avaliar um método alternativo de purificação do etanol, com intuito de identificar pontos de alto consumo energético e otimizar seu uso.
\end{abstract}

\section{INTRODUÇÃO (FONTE 14)}

O setor produtivo de etanol combustível é atualmente responsável por parcela importante da matriz energética brasileira. Juntamente com o bagaço da cana, perfazem $41,1 \%$ da oferta interna de energia de fontes renováveis do país. No biênio 2014/15, houve uma expansão de 5,8\% no setor, enquanto a oferta total de energia reduziu 1,3\% neste período (Resenha Energética Brasileira, 2016).

A agroindústria sucroalcooleira é, portanto, um setor bem estabelecido e importante na composição do PIB brasileiro. Além do etanol combustível, o setor também produz eletricidade por meio do sistema conhecido por cogeração, em que o bagaço da cana moída é utilizado como combustível para produção de vapor e acionamento de geradores elétricos via turbinas a gás. Este setor respondeu por 7,5\% da eletricidade ofertada no país em 2015 (Resenha Energética Brasileira, 2016).

\subsection{Extração Líquido-Líquido}

A extração líquido-líquido é uma metodologia alternativa para purificação de compostos, possível de ser empregada quando a destilação torna-se ineficiente ou promove inativação da substância de interesse, como no caso de compostos termossensíveis (enzimas, antibióticos, etc...) (ALBERTSSON, 1986). No caso da produção de etanol combustível, o interesse deve-se à possível utilização do butanol também como combustível futuramente (TRINDADE \& DOS SANTOS, 2017), o que gerará uma demanda por uma substância capaz de cumprir dupla função: além da já prevista, atuar também como solvente extrator (OFFEMAN et al., 2005a,b; RAHMAN et al., 2001; SCHNEIDER et al, 2015).

A expectativa é obter uma corrente extrato com menor concentração possível de água, de modo que a mistura a ser destilada seja composta essencialmente por etanol e solvente 
extrator. No caso do 1-butanol, observa-se que a mistura não apresenta ponto de azeotropia, como é visível no diagrama de equilíbrio líquido-vapor ilustrado na Figura 1:

Figura 1 - Diagrama de equilíbrio líquido-vapor para o sistema etanol + 1-butanol

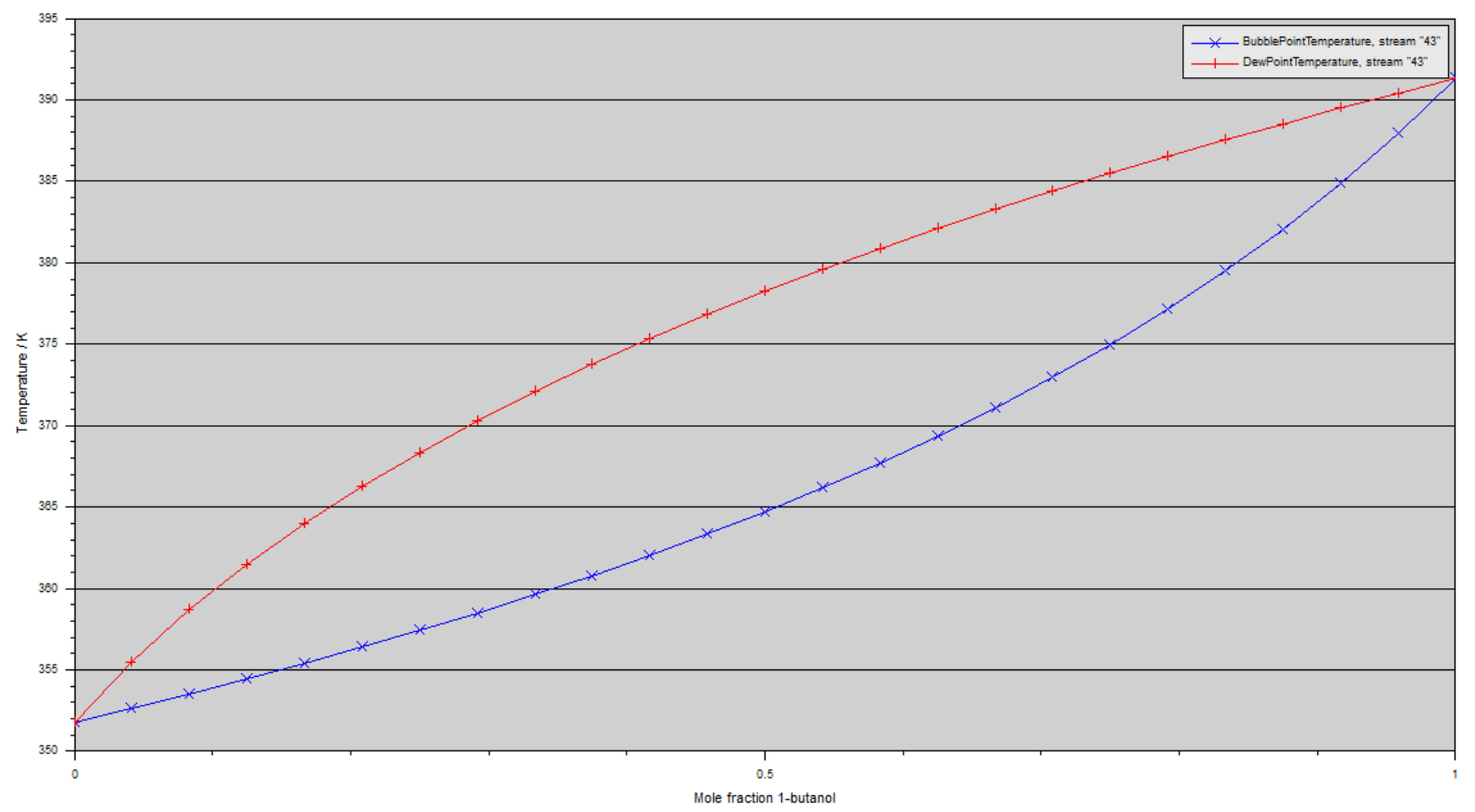

Evitando-se a azeotropia, é teoricamente possível minimizar o número de operações unitárias necessárias à obtenção de etanol anidro. No caso deste trabalho, em lugar da seção de desidratação passa a existir uma etapa de extração líquido-líquido, cujo requerimento energético é consideravelmente inferior.

\section{OBJETIVOS}

Neste trabalho, os principais objetivos foram:

a) Verificar a viabilidade da simulação computacional como ferramenta para avaliação de um processo químico industrial;

b) Estudar a aplicabilidade da extração líquido-líquido no refino de etanol combustível;

c) Comparar o processo proposto com um processo usual, observando-se as respectivas vantagens e desvantagens.

\section{MATERIAL E MÉTODOS}

Utilizou-se o software COCO Simulator, de distribuição gratuita e voltado à simulação de processos químicos. O software já foi empregado em diversas situações com sucesso (ELISIARIO, 2013). Os cálculos efetivos são realizados pelo ChemSep (KOOIJMAN \& TAYLOR, 1992). 
Tomou-se como base o fluxograma descrito em MARQUINI et al. (2007), ilustrado na Figura 2. Primeiramente o processo descrito por estes autores foi simulado para validação e posterior comparação com o aqui proposto. Esta escolha deveu-se pela simplicidade e por se tratar de um processo cujos dados foram obtidos juntamente a uma planta real.

Figura 2 - Processo de destilação descrito em MARQUINI et al. (2007)

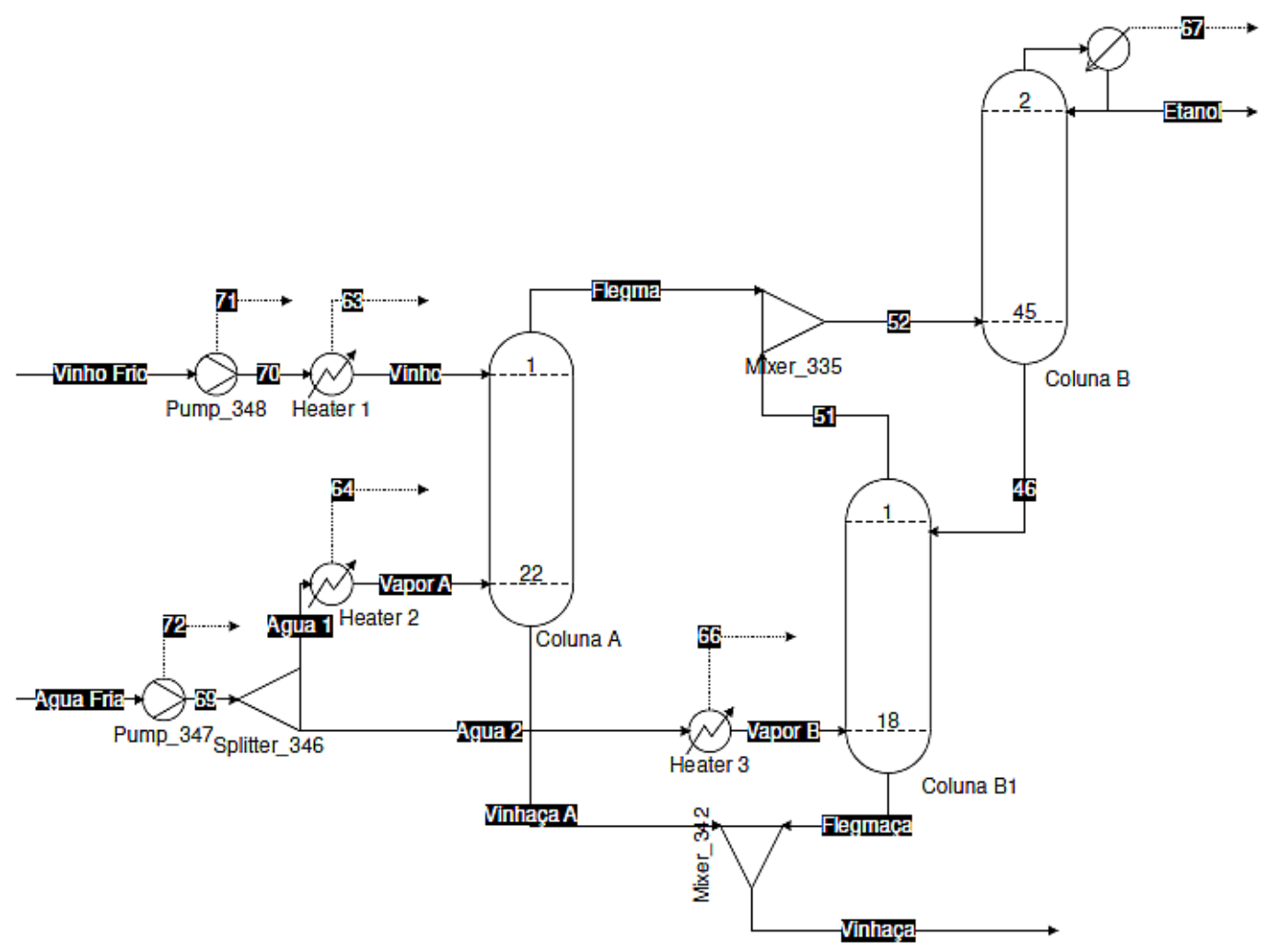

Em seguida, o processo alternativo foi desenvolvido no mesmo software. Partiu-se de um modelo de extrator líquido-líquido, com alimentação composta por uma corrente representativa do vinho e outra do solvente extrator. Como já descrito, o solvente escolhido para estudos iniciais foi o 1-butanol por ser um álcool, ou seja, possivelmente um bom extrator para a substância desejada e por apresentar miscibilidade parcial com a água. Considerou-se até o momento que o caldo fermentado (vinho) é uma mistura binária de água com fração mássica igual a 0,9388 e etanol 0,0612, que é o vinho descrito em MARQUINI et al. (2007). Em ambas simulações, o vinho foi admitido a 298,15 K (temperatura ambiente).

Como o extrator normalmente não produz correntes que se possa considerar isentas em nenhum dos componentes, colunas de destilação foram acrescentadas e otimizadas, com os objetivos de purificar o etanol e recuperar o solvente utilizado.

O modelo termodinâmico escolhido para cálculo do equilíbrio de fases nos equipamentos foi o UNIFAC (UNIquac Functional group Activity Coefficient) (FREDENSLUND et al., 1975) em sua formulação original, o que permitiu representar todas 
as interações entre componentes das misturas. O processo alternativo está ilustrado na Figura 3.

Figura 3 - Processo com extração líquido-líquido

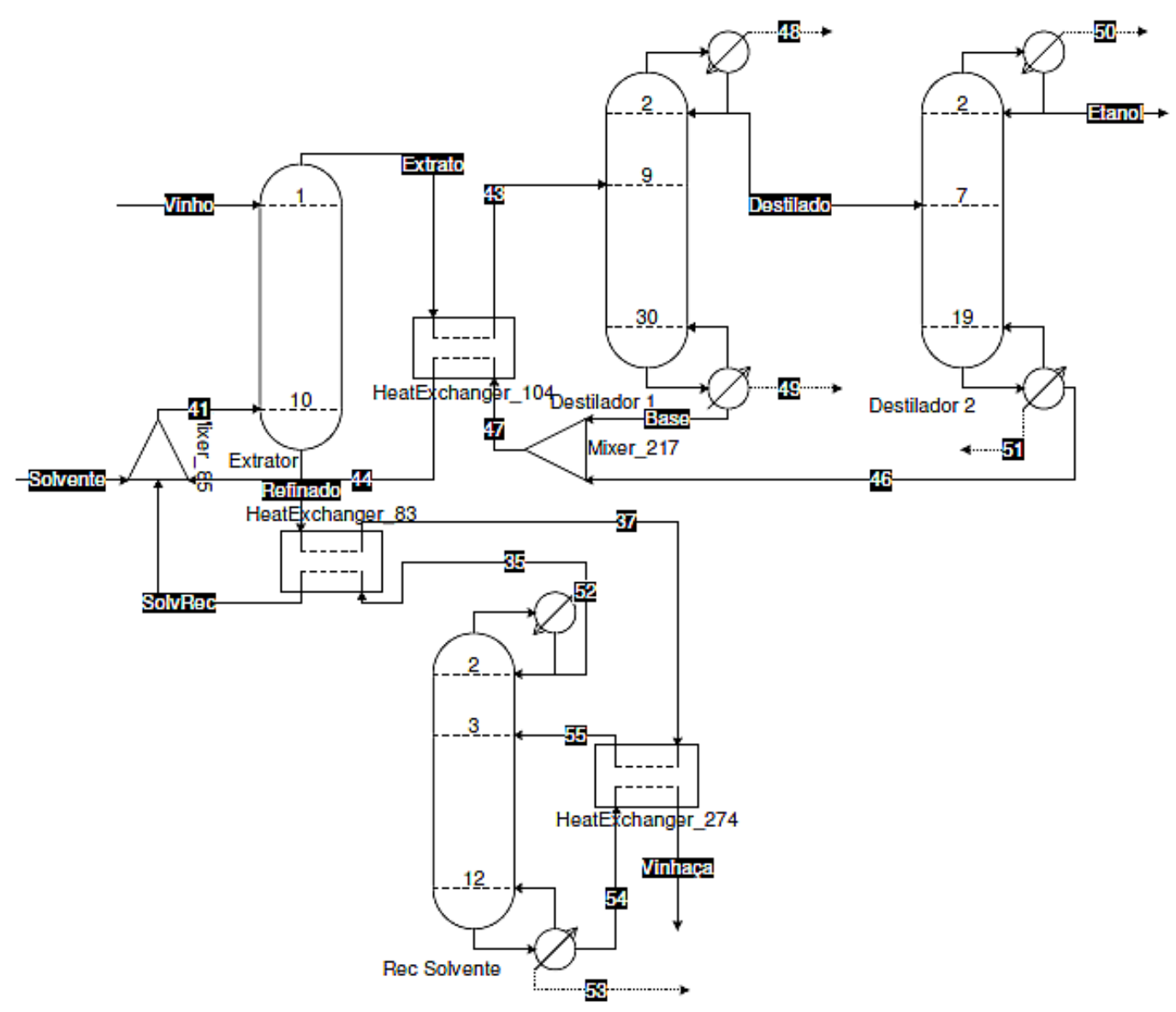

\section{RESULTADOS E DISCUSSÃO}

Os resultados obtidos até o momento indicam que é tecnicamente viável acrescentar uma etapa extrativa no processo de obtenção de etanol combustível. O solvente testado até o momento (1-butanol) possui miscibilidade relativamente elevada em ambas as fases, o que resulta em uma fase refinado com teor razoável de solvente e também de etanol e consequentemente uma coluna de destilação relativamente grande para tratamento da vinhaça. Em outras palavras, isto significa um consumo elevado de energia.

Não se obteve até o momento um processo idêntico ao descrito por MARQUINI et al. (2007), em que a formação de fase vapor dentro das colunas ocorre por injeção direta de vapor. Entretanto, o processo obtido é bastante semelhante, permitindo comparações numéricas. Com relação às composições das correntes de saída, pode-se montar a comparação ilustrada na Tabela 1: 
Tabela 1: Comparativo dos resultados obtidos

\begin{tabular}{|c|c|c|c|c|}
\hline \multirow[t]{3}{*}{ Corrente } & \multicolumn{4}{|c|}{ Composição em Massa } \\
\hline & \multicolumn{2}{|r|}{ Etanol } & \multicolumn{2}{|c|}{ Água } \\
\hline & Este Trabalho & MARQUINI et al. (2007) & Este Trabe & NI et al. (2007) \\
\hline Vinhaça & $7,53 * 10^{-6}$ & $3,06^{*} 10^{-6}$ & $\sim 1$ & $\sim 1$ \\
\hline Etanol & 0,927 & 0,932 & 0,073 & 0,068 \\
\hline
\end{tabular}

Quanto ao consumo de solvente extrator, observe-se que há apenas reposição das perdas nas correntes de saída, que são mínimas. A estimativa fornecida pela simulação é de apenas $0,018 \mathrm{~kg} / \mathrm{h}$ para esta reposição, aproximadamente.

Não se obteve uma corrente extrato suficientemente isenta de água para viabilizar a corrente de etanol de composição anidra. Porém, visto que há muitas variáveis de manipulação possível, acredita-se que isto seja possível, bem como reduzir a perda de etanol na corrente vinhaça.

\section{CONCLUSÃO}

A simulação apresentada neste trabalho demonstra a viabilidade da técnica de extração líquido-líquido aplicada à produção de etanol. Como modifica apenas parte do processo de refino do combustível, sem influência na parte fermentativa, o impacto econômico de sua adoção é relativamente pequeno, consistindo no acréscimo de uma coluna extratora e algumas modificações nas colunas de destilação. Por outro lado, pesquisas adicionais ainda são necessárias para definir um solvente de ótimo desempenho e minimizar o aumento na quantidade de vapor de aquecimento consumido. Também planeja-se acrescentar no vinho substâncias representativas do óleo fusel. A expectativa futura é de se obter um processo em que o etanol seja mais facilmente separado da fase aquosa, com economia de energia.

\section{REFERÊNCIAS}

ELISIARIO, A. C. M. Simulação Computacional E Análise Paramétrica De Uma Unidade Industrial De Descarga E Estocagem De Amônia Líquida Pressurizada. Dissertação (Mestrado), Universidade Federal de Uberlândia, Uberlândia, 2013.

FREDENSLUND, A., JONES, R. L., PRAUSNITZ, J. M., Group-Contribution Estimation of Activity Coefficients in Nonideal Liquid Mixtures, AIChE J., 1975, v. 21, p. 1086.

KOOIJMAN, H. A., TAYLOR, R., ChemSep - Another Software System for the simulation of Separation Processes, CACHE News, No. 35, Fall 1992, p. 1-9.

MARQUINI, M. F.; MARIANI, D. C.; MEIRELlES, A. J. A.; dos SANTOS, O. A. A.; JORGE, L. M. M. Simulação e análise de um sistema industrial de colunas de destilação de etanol. Acta Sci. Technol. 2007, v. 29, n. 1, pp. 23-28. 
OFFEMAN, R. D, STEPHENSON, S. K., ROBERTSON, G. H., ORTS, W. J. Solvent extraction of ethanol from aqueous solutions. I. Screening methodology for solvents. Ind. Eng. Chem. Res., 2005, n. 44, p. 6789-6796.

OFFEMAN, R. D, STEPHENSON, S. K., ROBERTSON, G. H., ORTS, W. J. Solvent extraction of ethanol from aqueous solutions. II. Linear, Branched, and RingContaining Alcohol Solvents. Ind. Eng. Chem. Res., 2005, n. 44, p. 6797-6803.

RAHMAN, M. A., RAHMAN, M. S., NABI, M. N. Extraction of ethanol from aqueous solution by solvent extraction-liquid-liquid equilibrium of ethanol-water-1-butanol, ethanol-water-1-pentanol and ethanol-water-1-hexanol systems. Indian Journal of Chemical Technology, set. 2001, v. 8, p. 385-389.

SCHNEIDER, L. T., TELEKEN, J. G., BONASSA, G, OLIVEIRA, C. J, MEIER, T. R. W., BERTÉ, E. I., TELEKEN, J. T. Otimização do processo de destilação em planta piloto para produção de etanol hidratado. Revista Brasileira de Energias Renováveis, 2015, v.4, p. 105- 118 . 